\title{
Para um aumento da criatividade dos estudantes *
}

Tem-se abusado muito da palavra "criatividade" porque é difícil defini-la com precisão. Na linguagem corrente, é muitas vezes usada com um sentido negativo: os educadores, os políticos e os administradores são criticados por "não serem criativos", mas, numa segunda análise, essa crítica significa em muitos casos apenas que o crítico não aprova o que o educador, o político ou o administrador estão a fazer. Na sociedade americana, onde se tende a adorar o que é novo e a condenar o que é velho, a palavra "criativo" é um adjectivo positivo, uma palavra de aprovação, enquanto que a frase muito usada "falta de criatividade" é uma expressão de condenação.

O dicionário não ajuda muito. O Webster's Unabridged Dictionary refere, por um lado, criatividade como "fazer qualquer coisa a partir do nada", tal como na Bíblia, onde Deus criou a terra, e por outro lado, refere actos sociais ou legais, como no governo onde o congresso cria uma nova lei, ou actos artísticos em que um pintor ou escultor cria uma obra de arte.

Nenhuma destas definições é satisfatória quando consideramos criatividade na ciência ou na formação de cientistas e engenheiros. Dentro deste contexto, prefiro uma definição que ouvi uma vez a um psicólogo. Um acto criativo é aquele em que se mostra pela primeira vez que duas ideias ou conceitos, antes considerados como totalmente separados, estão intimamente relacionados. Por outras palavras, um acto criativo é mostrar que duas ideias ou conceitos aparentemente distintos não são, de facto, distintos, mas apenas dois aspectos de uma ideia ou conceito mais gerais e unificados. Esta definição ajuda-nos a encontrar maneira de encorajar a criatividade nos estudantes de engenharia química, especialmente os estudantes graduados*.

Permitam-me agora ilustrar esta definição de criatividade com alguns exemplos tirados da história da Ciência e seguidamente indicar como essa definição sugere algumas maneiras úteis para formar cientistas e engenheiros criativos.

A história da termodinâmica dá-nos um exemplo notável. Até cerca de 1870 , a termodinâmica (tal como o nome implica) era a ciência das máquinas térmicas, uma ciência que estudava os princípios que regem a conversão de calor em trabalho mecânico e vice-versa. O trabalho de Mayer, Joule e Carnot mostrou que esta conversão pode ser descrita quantitativamente através de relações matemáticas simples que, contudo, são caracterizadas por uma falta de simetria; as leis para a conversão do trabalho em calor não são as mesmas que as que se aplicam à conversão do calor em trabalho. Foi esta falta de simetria que levou Clausius ao

\footnotetext{
* Licenciados a efectuar mestrado ou doutoramento.
}

conceito de entropia e à formulação quantitativa da $1 .^{\mathrm{a}} \mathrm{e}$ da $2 .^{\mathrm{a}}$ leis da termodinâmica.

Enquanto decorria este desenvolvimento teórico da termodinâmica havia simultaneamente um desenvolvimento experimental significativo na química, onde os pioneiros do que agora chamamos química-física mediam rendimentos de reacções químicas e distribuições de componentes de misturas entre duas ou mais fases. Até cerca de 1870 , ninguém reconheceu que havia uma ligação fundamental entre o que agora chamamos equilíbrio químico e o equilíbrio de fases. Mais importante ainda, ninguém até essa altura viu qualquer ligação entre estes fenómenos químicos e os princípios científicos das máquinas térmicas. Agora, mais de 100 anos depois, reconhecemos essa lição devido às nossas concepções de assimetria e irreversibilidade: é fácil converter trabalho em calor mas não é fácil inverter o processo; é fácil obter água e dióxido de carbono a partir de metano e oxigénio mas não é fácil fazer o contrário; é fácil misturar água e álcool mas, depois de os termos misturado, não é fácil separá-los até ao seu estado inicial.

Todos sabemos que foi Gibbs quem primeiro reconheceu a ligação entre a química-física e a termodinâmica, duas ciências que, antes de Gibbs, se acreditava não estarem relacionadas. Através da sua invenção de um conceito unificador - o potencial químico - Gibbs contruiu um suporte teórico que influenciou enormemente e fez progredir muitas áreas da ciência, com efeitos particularmente benéficos na engenharia quimica. A acção unificadora de Gibbs, mostrando a relação entre domínios de investigação aparentemente separados, é um exemplo notável do sentido que damos ao termo criatividade.

O trabalho criativo de Gibbs ligou uma ciência a outra; ele usou os princípios científicos das máquinas térmicas para obter um tratamento teórico do equilibrio em sistemas químicos. Contudo, a essência da criatividade - relacionar duas ideias separadas - não necessita de ser limitada àqueles casos em que ambas as ideias provêm do mundo da ciência.

Os actos criativos interrelacionam ideias independentemente da sua origem ou classificação. Por exemplo, as notas autobiográficas de Sigmund Freud revelam que a psicanálise nasceu da interacção de dois factores principais. Freud trabalhou quando era novo num hospital psiquiátrico em Paris, onde tratou mulheres atacadas de histeria; por outro lado, Freud tinha lido os traba-

* Traduzido do Chemical Engineering Education, Vol. 19, Pág. 22 (1985) com as autorizaçōes do Autor do artigo e do Editor da revista. Tradução de Susana Barreiros e Edmundo G. Azevedo.

a Departamento de Engenharia Quimica, Universidade da Califórnia, Berkeley, CA 94720, E.U.A. 
lhos filosóficos de Friedrich Nietzsche e ficado marcado pela observação de Nietzsche de que o comportamento humano era apenas superficialmente condicionado pelas regras racionais da sociedade, enquanto que em actos essenciais o comportamento humano era governado por motivos profundos e irracionais. Freud viu a relação entre estes dois factos e estabeleceu os hoje bem conhecidos conceitos de id e de super ego que lhe permitiam interpretar a histeria como uma consequência de emoções reprimidas normalmente provenientes dos primeiros tempos de infância; uma vez reconhecida pela doente a origem do problema, ela podia, com assistência adequada, conseguir uma adaptação que em muitos casos levava à cura. $\mathrm{O}$ acto criativo de Freud foi aplicar à medicina o que na época era uma filosifia estranha e radical.

Um terceiro e último exemplo é dado pelo físico Niels Bohr, cuja teoria da complementaridade é hoje aceite pela maioria dos cientistas como uma das pedras basilares da física. Esta teoria, também conhecida como a interpretação de Copenhaga da mecânica quântica, é um conceito da natureza que acredita que a dualidade nâo é um fenómeno aparente mas sim uma característica fundamental dos fenómenos naturais: a luz não é unicamente corpuscular assim como não é apenas uma onda. É ambas as coisas, de tal modo que, consoante a observação que queremos interpretar, uma ou outra daquelas características é mais evidente. Se a dualidade é fundamental, então a causalidade clássica e o determinismo não são possíveis, como mostra o princípio da incerteza de Heisenberg. De acordo com o ponto de vista da teoria desenvolvida em Copenhaga, probabilidades e estatística não são apenas aproximações que resultam do nosso conhecimento deficiente; são sim as leis fundamentais que regem os fenómenos naturais. Diz-nos Bohr que a sua teoria da complementaridade tem duas origens: a espectroscopia e a filosofia de Sorren Kierkegaard, um dinamarquês como Bohr, que se opôs asperamente à filosofia determinística de Hegel que dominou a Europa durante o século dezanove. A famosa sequência de Hegel (tese, antítese, síntese) exprimia a noção de que, com o tempo, e tal como um pêndulo, uma determinada ideia (ou tese) gera o seu oposto (antítese) e que com mais tempo, as duas ideias opostas convergem para formar uma nova ideia (síntese). Kierkegaard era um cristão profundamente religioso que duvidava que o homem pudesse alguma vez atingir o conhecimento absoluto; tal conhecimento estava reservado para Deus. Kierkegaard negava que com o tempo uma ideia fosse seguida pela sua oposta; pelo contrário, ele realçou a sua convicção de que duas ideias opostas existem simultaneamente. Os opostos coexistem e se examinarmos qualquer verdade profunda, verificamos que o seu oposto também é verdadeiro. A ideia de Kierkegaard está sucintamente expressa no titulo de um dos seus livros, Either/Or.

Bohr estudou a obra de Kierkegaard durante a sua juventude, pouco antes de se interessar pela interpretação das transições entre níveis de energia electrónicos, medidas pelos espectroscopistas, Antes de Bohr, a maioria dos físicos nunca tinha ouvido falar de Kierkegaard e, mesmo que tivessem, nunca lhes teria ocorrido que a crítica altamente abstracta de Kierkegaard à obra de Hegel tivesse qualquer ligação com transições electrónicas. Mas Bohr viu a relação entre uma coisa e a outra. $\mathrm{O}$ seu acto criativo foi estabelecer uma interpretação de fenómenos físicos usando conceitos a partir do que era (e ainda é) uma filosofia obscura.
O que é que estes exemplos sugerem para a promoção da criatividade na Educação? Se aceitarmos a definição de criatividade que indiquei, temos de fazer com que os nossos estudantes sejam expostos a uma variedade de assuntos, incluindo alguns que estão longe da engenharia quimica. Se a essência da criatividade é fazer qualquer coisa nova ou fazer qualquer coisa de uma maneira diferente, então devemos dar aos nossos estudantes as ferramentas intelectuais necessárias para serem criativos; para conseguir isso, os nossos estudantes devem familiarizar-se com maneiras de pensar e espírito crítico diferentes daquelas que usamos vulgarmente em engenharia química. Ou seja, a abertura intelectual é um estímulo potencial para a criatividade. $\mathrm{O}$ argumento mais vulgar para esta abertura é o de que, para ter sucesso profissional, um engenheiro quimico deve não só ser tecnicamente competente, mas também ter conhecimentos de economia e possuir qualidades humanas que lhe permitam interactuar de forma positiva com um largo espectro de colaboradores e que, de uma maneira geral, fazem dele uma pessoa bem aceite. Um outro argumento é que os licenciados são não só engenheiros químicos mas também seres humanos inteligentes que procuram preencher as suas horas de lazer com algo que lhes dê prazer, e por isso é lógico incluir música, arte e literatura num curriculum de engenharia química. Sem desmerecer o peso destes argumentos, acrescentaria que aquela abertura é necessária à criatividade, não necessariamente para produzir um Gibbs, um Freud ou um Bohr - porque isso é pouco provável - mas dotar os nossos licenciados de uma atitude aberta em relação a problemas que é provável virem a encontrar, para lhes dar a capacidade de pensarem para além da engenharia química quando como concerteza acontecerá - enfrentarem aqueles desafios que não podem ser resolvidos pelo bom senso convencional contido na engenharia química standard. Em qualquer área de realização humana, o progresso consegue-se na maior parte das vezes através de contribuiçōes provenientes de outra áreas. Os grandes avanços efectuados recentemente na medicina e na biologia são devidos principalmente ao desenvolvimento da física experimental e da química analítica. Hoje em dia os médicos podem diagnosticar problemas patológicos até agora difíceis de detectar usando a tomografia axial computorizada. Esta técnica utiliza tecnologia sofisticada de raios $\mathrm{X}$ conjuntamente com computadores. Por outro lado, descobertas recntes em biologia molecular que prometem levar à cura doenças graves, só são possíveis devido aos poderosos microscópicos electrónicos, cromatógrafos sofisticados e detectores de radiação isotópica de grande sensibilidade. Do mesmo modo, independentemente das opiniões que possamos ter acerca da arte e da música modernas, reconhecemos que as novas formas de arte que estão a aparecer nos E.U.A. e na Europa, são cada vez mais influenciadas pelos contactos que os nossos artistas e músicos têm com culturas não-ocidentais, principalmente africanas, e com a electrónica, incluindo o computador. A razão por que faço referência a tudo isto é realçar uma vez mais que o progresso resulta duma fertilização cruza$\mathrm{da}$, e acentuar que em qualquer área de actividade humana apenas se atinge a novidade importante indo para além das fronteiras dessa área, através da utilização dos avanços obtidos nas outras áreas.

Permitam-me que conclua com uma breve reflexão sobre como estas ideias gerais de abertura e criatividade podem ser postas em prática, tendo em conta as 